\title{
Self-organisation and motion in plants
}

\section{Lenau, Torben Anker; Hesselberg, T.}

Published in:

Bioinspiration, Biomimetics, and Bioreplication 2014

Link to article, DOI:

$10.1117 / 12.2045155$

Publication date:

2014

Document Version

Peer reviewed version

Link back to DTU Orbit

Citation (APA):

Lenau, T. A., \& Hesselberg, T. (2014). Self-organisation and motion in plants. In A. Lakhtakia, \& R. J. MartínPalma (Eds.), Bioinspiration, Biomimetics, and Bioreplication 2014 (Vol. 9055). [90550F] SPIE - International Society for Optical Engineering. Proceedings of SPIE - The International Society for Optical Engineering https://doi.org/10.1117/12.2045155

\section{General rights}

Copyright and moral rights for the publications made accessible in the public portal are retained by the authors and/or other copyright owners and it is a condition of accessing publications that users recognise and abide by the legal requirements associated with these rights.

- Users may download and print one copy of any publication from the public portal for the purpose of private study or research.

- You may not further distribute the material or use it for any profit-making activity or commercial gain

- You may freely distribute the URL identifying the publication in the public portal

If you believe that this document breaches copyright please contact us providing details, and we will remove access to the work immediately and investigate your claim. 


\title{
Self-organisation and motion in plants
}

\author{
T.A. Lenau*a, T. Hesselberg ${ }^{\mathrm{b}}$ \\ ${ }^{a}$ Dep. of Mechanical Engineering, Technical University of Denmark, Build. 426B, DK2800 \\ Lyngby, Denmark; ${ }^{b}$ Department of Zoology, University of Oxford, Oxford OX1 3PS, United \\ Kingdom
}

\begin{abstract}
Self-organisation appeals to humans because difficult and repeated actions can be avoided through automation via bottom-up nonhierarchical processes. This is in contrast to the top-level controlled action strategy normally applied in automated products and in manufacturing. There are many situations where it is required that objects perform an action dependent on external stimuli. An example is automatic window blinds that open or closes in response to sunlight level. However, simpler and more robust designs could be made using the self-organising principles for movement found in many plants. Plants move to adapt to external conditions, e.g. sun-flower buds tracking the sun, touch-me-not Mimosa and Venus fly trap responding to mechanical stimuli by closing leaves to protect them and capture insects respectively. This paper describes 3 of the basic biomimetic principles used by plants to track the sun; i) light causing an inhibiting effect on the illuminated side causing it to bend, ii) light inducing a signal from the illuminated side that causes an action on the darker side and iii) light illuminating a number of sensing plates pointing upwards at an angle activate an expansion on the same side. A concept for mimicking the second principle is presented. It is a very simple and possible reliable self-organising structure that aligns a plate perpendicular to the source of illumination.
\end{abstract}

Keywords: Self-organisation, plant motion, sun tracking, heliotropism, phototropism

\section{INTRODUCTION}

Self-organisation as a means for controlling light is highly relevant in a number of different areas. One area is bringing daylight into dark areas of buildings like corridors, bathrooms and cellars. Apart from private housing it is also very relevant within professional buildings like offices and shopping centers. The potential benefits include large energy savings since the amount of electrical lighting can be reduced and better well-being for the people occupying the rooms. Daylight has positive physiological and psychological effects compared to artificial lighting due the spectral distribution of the light and to the changing intensity and colour temperature during the day ${ }^{1}$. Present solutions to bringing daylight into buildings include passive sun tunnels ${ }^{2,3}$, active systems ${ }^{4,5}$ like fibre-optics solutions and light wells ${ }^{6}$. Sun wells are widely used in southern European countries where they serve the combined purpose of bringing daylight deeper into the building and provide ventilation. However even under very favourable daylight conditions the sun wells normally perform quite poorly making the use of additional electrical lighting necessary just a few meters into the building ${ }^{6}$. The sun tunnels have thanks to a high reflective tube a better light conducting performance typically allowing between 4007000 lumen into rooms through a $0.1 \mathrm{~m}^{2}$ light-tube $\mathrm{e}^{2,3}$. The sun tunnels are passive constructions and are therefore normally dependent on the ambient light available. Active tracking systems rely on electrical sensors and actuators and use either reflective tubes or polymer light guides to transport the light. Yields are much larger for the active systems but limitations include the energy consumption, long term reliability and light quality when light guides are used.

Another area is voltaic solar cells and solar panels for water heating. Most existing solutions are mounted with a fixed angle facing south and will therefore have lower yield than from an optimal position facing the sun. Experiments have shown that a $65 \%$ increase in energy yield can be achieved through actively tracking the sun ${ }^{7}$. However present systems for active sun tracking require mechanical solutions for detecting the direction of the incoming light and moving the collector causing energy consumption and resulting in a more vulnerable system.

\subsection{Self-organisation}

Self-organisation is a process where a certain order is achieved through the local interactions between the components of an initially disordered system. The process is solely dependent on the emergent properties of the components and will 
take place without any need for external centralised control. Self-organisation is seen many places in nature as described by Lenau and Hesselberg ${ }^{8}$. One example is the behaviour of large flocks of birds and fishes. Following very simple local rules the birds and fishes are able to quickly change the direction of motion by only coordinating with the closest neighbours. Another example is the behaviour of the slime mould Physarum polycephalum. The slime mould is selforganised and bases its optimization only on locally available information?. It was used to compare the network performance in the Tokyo rail network with a network created by the slime mould. The Tokyo rail network was mimicked by placing oat-flakes at positions matching the rail stations. The remarkable results show that the slime mould has a network performance that is comparable to the one of the railway network.

\section{SUN TRACKING IN PLANTS}

Plants are often regarded as stationary organisms. However, most plants have very active motion where leaves, flowers and even stems can change their physical position when stimulated. An example of a plant that is not bound to a specific position is the Spanish moss Tillandsia usneoides ${ }^{10}$. It has no roots but only a stem and scaled leaves that extract water and nutrients from the air. They are normally hanging from branches on trees but can be taken by the wind and transported to other locations.

\subsection{Stimulated motion}

Stimulated motion can be seen in many plants and is often a self-organised local phenomenon where parts of the plant have emergent properties causing it to exhibit certain behaviour when exposed to stimuli.

We usually think of plants as immobile organisms that only change slowly through growth by cell division and cell elongation. However, some plants are capable of fast movement that rivals or even outcompetes muscle actuated movements in animals ${ }^{11}$. Generally, plants have evolved fast movements for one of three major reasons.

i) To disperse spores, pollen or seeds. Wind-pollinated plants often face the problem of getting the minute spore and pollen grains away from the still boundary layer around the parent plants and into the turbulent air where the wind can carry them large distances. The sphagnum moss for instance have evolved an explosive dispersal of their spores from capsules, which generate enough force to propel the spores up to $20 \mathrm{~cm}$ above the moss ${ }^{12}$.

ii) To get nutrients. Carnivorous plants have evolved the ability to utilize small animals such as insects to obtain additional nutrients, in particular nitrogen, which allow them to grow as epiphytes on trees or in very nutrient poor soils including acidic bogs or rock outcrops. While some such as Nepenthes utilize passive traps, i.e. slippery pitchers with digestive fluid at the bottom, other plants rely on active spring-traps. The Venus fly trap for example traps insect within their modified leaves by rapidly closing them (in less than $100 \mathrm{~ms}$ ) if two or more hairs are triggered in rapid succession of each other ${ }^{13,14}$.

iii) To protect vital organs or obtain optimal light and temperature conditions. Some plants display relatively fast movement to bend their stalk and leaves toward the light in order to increase photosynthetic efficiency, whereas others, such as the Mimosa, close their leaves in response to touch to better protect them against herbivores. Within this group we also find plants that track the daily movement of the sun with their flowers, so-called flower heliotropism, in order to ensure an optimal temperature for their reproductive organs ${ }^{15}$.

Plants, unlike animals lack centralised control structures such as the central nervous system and specialised actuator structures such as muscles, so instead have to depend on localised simple mechanisms for generating movement. The primary mechanism is adjustment of cell hydration in order to increase or decrease water pressure, the so-called turgor pressure, within the individual cells. Leaves and stalks can for instance bend toward the sun utilizing special motor cells in the hinge of the leaf petiole, the so-called pulvinus, such that if cells on the upper-side of the pulvinis dehydrates, and thus become less rigid, while cells on the under-side hydrates, and thus become more rigid, the leaf will bend upwards ${ }^{16}$. Similar, although more complex, mechanisms are responsible for other types of plant movement. In the Sphagnum moss mentioned above, dehydration of the capsule containing the spores causes it to decrease in volume, which leads to an increase in internal pressure up to $500 \mathrm{kPa}$, which eventually results in the cap breaking free and the spores violently being propelled upwards ${ }^{16,12}$. In the Venus fly trap, the modified leaves are bi-stable and can be in either an open concave or a closed convex shape. The concave shape possesses a high elastic energy, so that when the transition is initiated, probably due to a rapid loss of turgor pressure, the shape change occurs within $100 \mathrm{~ms}^{11,14}$. The mechanism 
behind heliotropism is central to the topic of this paper and will therefore be discussed separately, but similar to the other mechanisms it also relies on changes in cell turgor pressure in the peduncle ${ }^{15}$.

While studies of plant biomechanics in general have proved a fruitful avenue for biomimetic concepts such as Velcro, the Lotus Effect and current efforts into developing crash helmets from the impact resistance of falling coconuts and other fruits, plants movements, despite their general fascination, has yet to generate significant biomimetic research ${ }^{13,16}$, ${ }^{11}$. To our knowledge no biomimetic research has yet been inspired by the explosive seed dispersal mechanism. However, the elastic shape change in the Venus fly trap has recently given inspiration to a novel type of shape-memory polymers. Holmes and Crosby ${ }^{17}$ developed a responsive surface of microlens shells capable of elastically snapping from a concave to a convex curvature when a critical stress developed in the shell structure. The resultant surface was found to respond two orders of magnitude faster than traditional shape-memory polymers ${ }^{17}$. Finally, the idea of the present paper to utilise heliotropism to develop more efficient solar cells or light catching structures is not novel. In 2008, a group of MIT students developed a prototype structure that utilised the concept of motor cells on different sides of a petiole or peduncle to allow the structure to bend in response to temperature differences between the light and shaded side of the structure. The prototype proved in principle that the structure could track the movement of the light entirely passively without the need for electrical motors ${ }^{18}$. The project resulted in the creation of a company, SunPoint Technologies Inc., which is currently exploring the commercial aspects in terms of increased solar cell efficiency.

\subsection{Heliotropism and phototropism}

Biologists differentiate between heliotropism (tracking the sun) and phototropism (tracking the light). The latter is wide spread amongst plants where it is used during the irreversible growth of the plant. The term heliotropism is usually used to describe the reversible movement of leaves and flowers in response to the position of the $\operatorname{sun}^{19}$.

As early as 1913, Blauuw made the observation that light could inhibit growth on Helianthus hypocotyls (stem of a germinating seedling on sunflowers) $)^{19}$. Much later Bruinsma and Hasegawa also studied the Helianthus hypocotyls and the oat coleoptile (the pale protective sheet covering emerging shoots). They argue that a growth inhibiting substance is accumulated at the irradiated side of the plant and that phototropic curvature is found even though the auxin distribution is uniform. Auxin is the name for a group of plant hormones involved in regulating plant growth. They act as signals to initiate both the slower plant growth from cell division as well as the potentially more rapid movement arising from cell elongation.

Helianthus (sunflowers) are often believed to track the sun, but studies disagree on whether the flower itself moves ${ }^{19}$. Leshem reports on the movement of the flower itself $\mathrm{f}^{20}$. However, it is more generally agreed that the shoot apex on the sunflower moves during the day from east to west and return to east during the night ${ }^{20,21}$, although the exact mechanism behind this remain unknown. In an experiment a sunflower plant was rotated 180 degrees and the shoot apex now moved from west to east and returned to west during the night ${ }^{19}$.

Went studied how the oat (Avena) coleoptile changed direction towards the light ${ }^{22}$. In an experiment he cut off the top 2 $\mathrm{mm}$ of the coleoptile and extracted a substance into gelatine. When the small blocks of the gelatine were placed on the one side of the coleoptile stumps the growth were accelerated in the same side. The growth accelerating substance is what later was named auxin ${ }^{19}$. The coleoptile tip produces more auxin on the shaded side which is explained by a lateral transport of the substance from the sunny side. This theory is referred to as the Cholodny-Went theory ${ }^{19}$.

The anemona Anemone rivularis exhibit heliotropism where flowers keep orientation towards the sun through most of the day ${ }^{15}$. The anemone is an alpine plant exposed to fluctuating temperatures and other climatic variability. Facing the sun, flowers and seeds has a better chance to develop successfully. Zhang and colleagues report that the tepals play an important role in the heliotropism ${ }^{15}$. In experiments, flowers where pistils and stamen are removed, induce sun-tracking of their stalks in an identical manner to intact flowers (see figure 1). But if the tepals are removed the peduncles do not move and the flower remains in a fixed position independently of the direction of light. The accuracy of the solar tracking is measured to be within $20 \%$. 

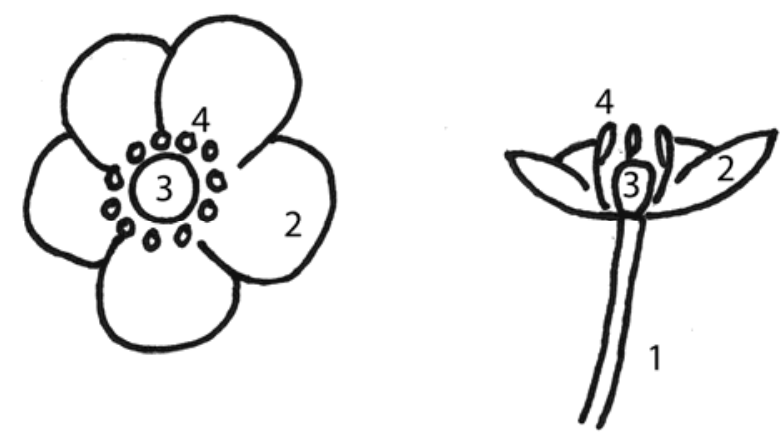

Figure 1. Flower structure for an anemone: 1: peduncles (stalk), 2: tepals, 3: pistils (female part) and 4: stamen (male part)

The flowers in snow buttercups Ranunculus adoneus also track the sun. As opposed to the anemone the light sensing areas are not placed in the flower itself but in the top part of the stalk ${ }^{23}$. This was shown by decapitating the flowers. The stalks without flowers kept tracking the sun. By shading different parts of the stalk it was shown that the light sensitive part was in the top end of the stalk.

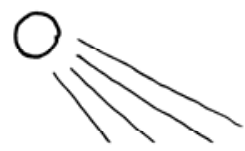

$A$
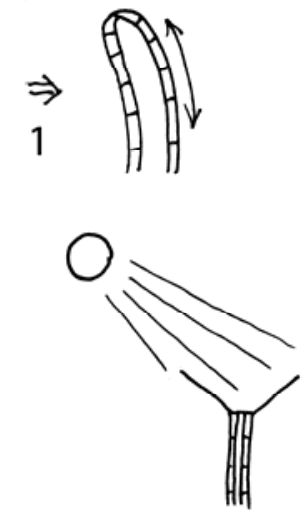
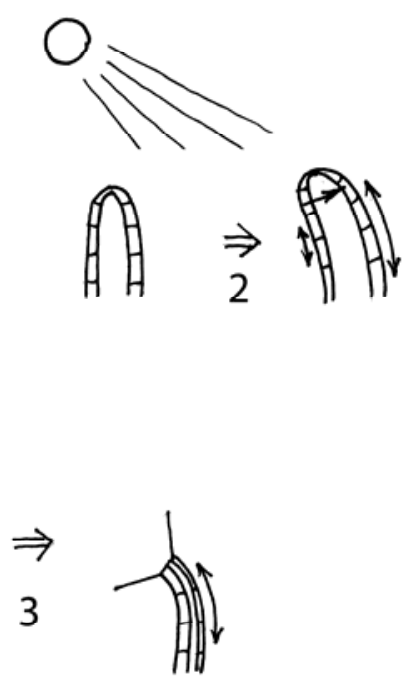

Figure 2. Plant stem bending principles: 1: Blauw/Bruinsma/Hasegawa principle (growth inhabitation on the illuminated side), 2: Cholodny-Went principle (growth advancing hormones transported to the dark side) and 3: Anemona principle (illuminated tepals stimulate growth).

\subsection{Basic sun tracking mechanisms}

As described above, phototropism/heliotropism can be either an irreversible process during plant growth or a reversible process during daily movements of plant leaves and flowers. However Häder ${ }^{19}$ argue that the basic mechanism is tugor driven cell-volume change (reversible), as seen in pulvinar phototropism, which is not fundamentally different from the growth mediated phototropism as seen in coleoptiles. We therefore formulate the following basic biomimetic principles from the different phenomena seen in plants:

Principle 1: The Blaauw/Bruinsma/Hasegawa theory assumes a growth inhibiting effect on the irradiated side of the plant ${ }^{19}$. The equivalent functional principle can be formulated as 'light causes an inhibiting effect on the illuminated side which together with a general expansion causes a bend towards the light'. This principle means that sensing and effect takes place at the same place and do not require signal transport. 
Principle 2: The Cholodny-Went theory assumes a lateral transport of the growth hormone auxin from the irradiated side of the plant tip. The assymetrical distribution of auxin is transmitted to lower parts of the plant causing a curvature in the growth $^{22,19}$. The equivalent functional principle can be formulated as 'light induces a signal from the illuminated side that causes an action on the dark side'. The principle requires signal transport from the light to the dark side.

Principle 3: The phototropic movement of the anemona suggests that the tepals on the dark side of the plant receive more light on their upper side, which activates expansion in a vertical direction which again causes the dark side of the peduncle to expand. The equivalent functional principle can be formulated as 'a number of light sensing plates pointing upwards at an angle activate an expansion on the same side as the plate'. This principle means that sensing and effect can take place at the same side meaning no signal transport is needed as long as the expansion mechanism is close to the sensing area. However, the anemone peduncle bends from top to bottom ${ }^{15}$ which indicates that vertical signalling takes place.

\section{PROPORTIONS OF SUN MOVEMENTS}

As mentioned previously a range of applications will benefit from sun tracking. The question is how much movement is required. To yield the most energy a tracking device should follow the sun from sunrise in east to sunset in west and from the horizon to zenith at noon.

Due to Earth's rotation the Sun is seen as moving daily from east to west causing the rhythm of the day. Since the Earth axis of rotation is around 23.5 degrees from a line parallel to the sun the position of the sun on the sky will differ depending of the time of the year. The height of the sun will vary with 47 degrees from summer to winter. On the Nordic hemisphere at 50 degrees latitude the noon sun height is around 63.5 degree at June solstice but only 16 degrees in December $^{24}$ as shown in figure 3 . This also affects the number of sun hours during the day from giving 16 hours of sun in the summer but only 8 hours in the winter. If a sun tracker placed at $50^{\circ} \mathrm{N}$ should track the sun all year round it should be able to turn laterally by $240^{\circ}$ and horizontally by $47^{\circ}$. At equator the movement should be $180^{\circ}$ laterally and $47^{\circ}$ horizontally.

However, since energy levels are highest in the middle of the day, smaller movements could be sufficient. Anemones are reported to track the sun within a 20 degree accuracy from 9-15 during the day. In this period the flowers turned their heads around 60 degrees $^{15}$. This was measured in the Himalayas in China at an elevation of 3.600 meters in June at the latitude 29 degree north. On the other hand if the purpose of the sun tracker is to reduce energy for lighting in houses it can be important to be able to track the sun for the full day.

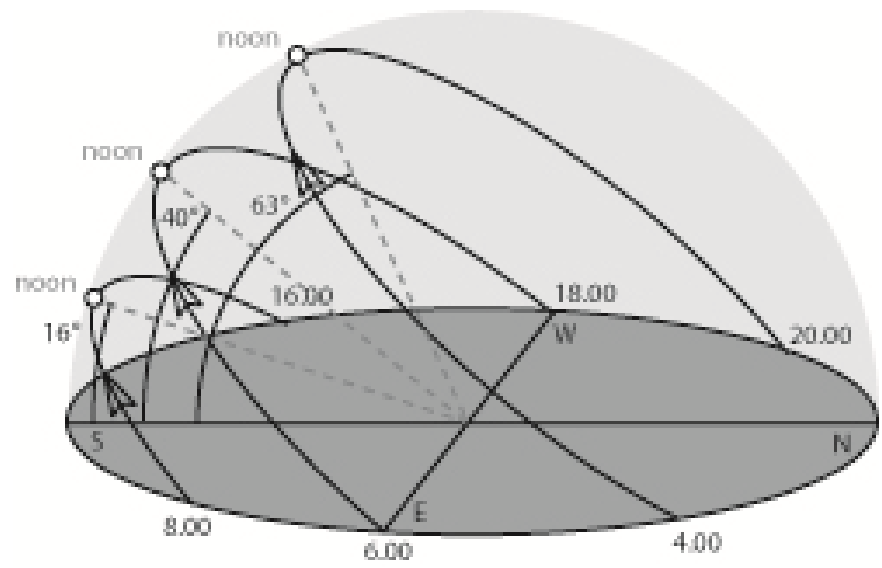

Figure 3. Height of the sun at $50^{\circ}$ north latitude during the day at June solstice (top curve), equinoxes (middle curve) and December solstice (bottom curve). Based on data from the Hermansen Almanak ${ }^{24}$.

\section{MIMICING SUN-TRACKING USING SELF-ORGANSATION PRINCIPLES}

A sun tracker that mimics the mechanisms from plants following the CholodnyWent theory needs to solve 3 tasks, namely how to detect the incoming sunlight, how to communicate a signal to an actuator and how to perform the motion. The incoming sunlight has a fairly broad spectrum of visible, ultraviolet and infrared light. Plants use the visible light, 
but it may be easier to make an artificial equivalent using infrared light meaning heat radiation. A low tech concept based on heating can be made using air-filled containers that acts as collectors of heat. The collectors are connected to actuators through flexible tubes. Depending on the suns angle to the collector the air pressure will change and the actuators will change position accordingly. A very simple version has two collectors pointing in perpendicular directions as shown in figure 4 . When the sun shines directly on one of the collectors the other one will be in shade. The sun movement from the one to the other collector changes the pressure in two collectors so it decreases in the first while increasing in the second. The pressure is transferred to the actuators that move accordingly. When the collector at left is heated by the rising sun, air pressure inside rises and causes the actuator at right to expand and turn the plate that should face the sun. As the sun moves, the air pressure in the left collector decreases while it increases in the right hand collector. This causes the actuators to turn the plate so it keeps facing the sun.

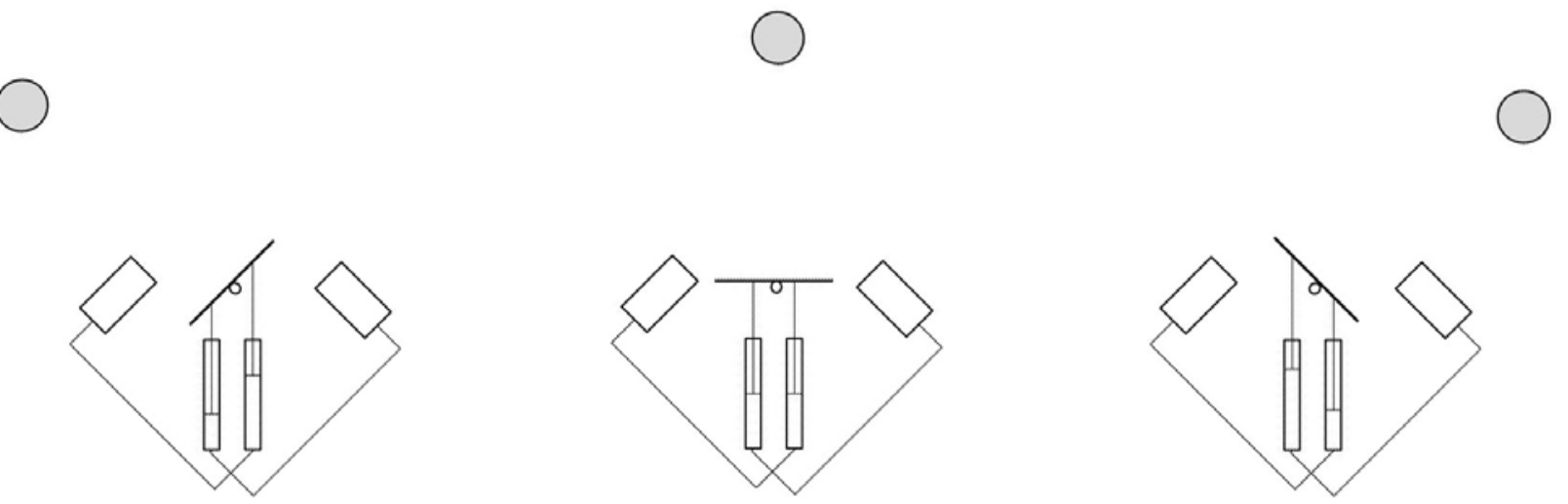

Figure 4. Schematic illustration of the motion of a biomimetic sun tracker based on the CholodnyWent principle.

The pressure $p$ in each collector will vary with temperature $t$ and temperature is proportional to the projected area $a_{p}$ perpendicular to the sun. The surface of the collector facing the sun has the area a, the angle of the sun is $\alpha$ and the pressure in the collector facing south-east is $\mathrm{p}_{1}$ and $\mathrm{p}_{2}$ in the one facing south-west. $\mathrm{P}_{0}$ is the initial pressure which is equal in both systems.

$$
\mathrm{a}_{\mathrm{p}}=\cos (\alpha) * \mathrm{a}, \mathrm{p} 1=\mathrm{p}_{0} * \cos (\alpha), \mathrm{p} 2=\mathrm{p}_{0} * \sin (\alpha)
$$

As seen in figure 5 , pressure decrease in collector 1 while increasing in collector 2 . The difference in pressure between the two systems follows a linear progression as long as the sun reaches both collectors. When only one collector is reached by the sun's rays the pressure is higher than $\mathrm{p}_{0}$ causing the tracker plate to stay in the one end position.

An advantageous inherent property of the simple concept is the low sensitivity to temperature fluctuations. The concept will work at low and high temperatures since it is the temperature difference between the two air pressure systems that causes the movement.

This system will track the sun exactly for a 90 degree movement which could be from 9 to 15 hours. In the remaining sun hours the trackers will be constant facing either south-east or south west and the amount of captured sunlight will be smaller as illustrated in figure 6. However the system will capture light all day from sunrise until sunset even though the amount is reduced towards the ends of the day. This is much better than solar collectors mounted at a fixed angle. They are only capable of collecting light in a 12 hour period (180 degree sun angle) and in this period only half of the potential light can be harvested.

Another challenge for a solar collector is the 47 degree horizontal variation depending of the time of the year. This can be solved using the presented system by combining two collector systems oriented perpendicular to each other so the one system follow the east-west movement and the other the horizontal movement. 


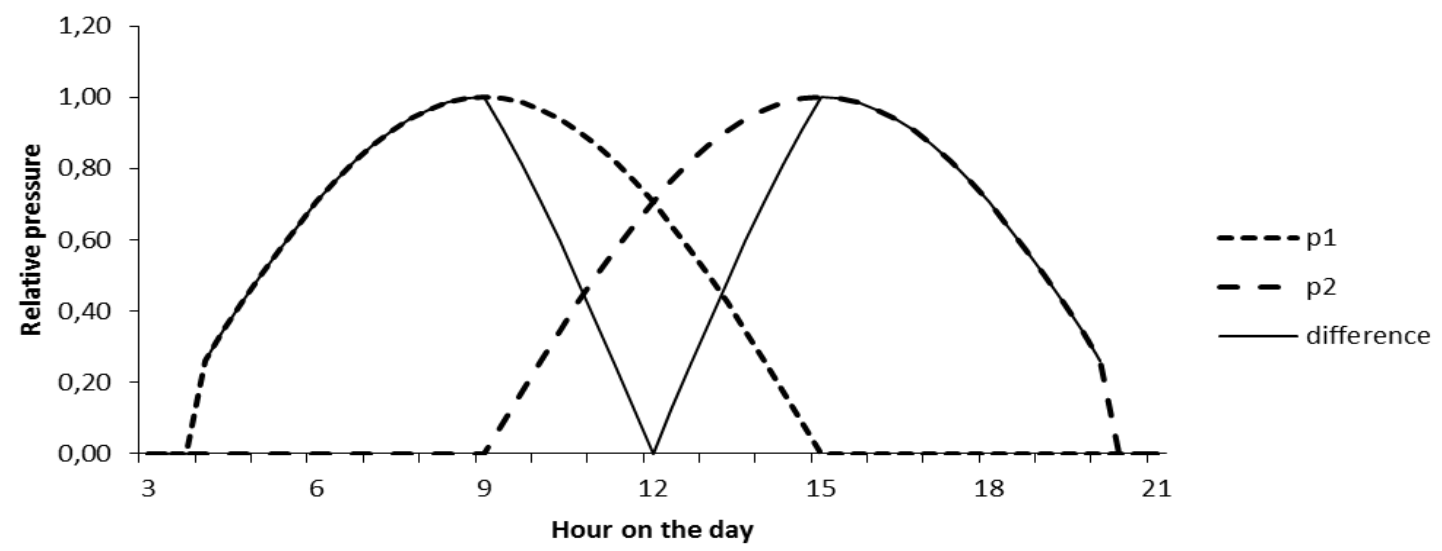

Figure 5. Pressure variation for two perpendicular collector containers. $P_{1}$ is the relative pressure in a collector facing southeast and $\mathrm{p}_{2}$ the relative pressure in the collector facing south-west. When the sun is midtway between them at noon the pressure is even.

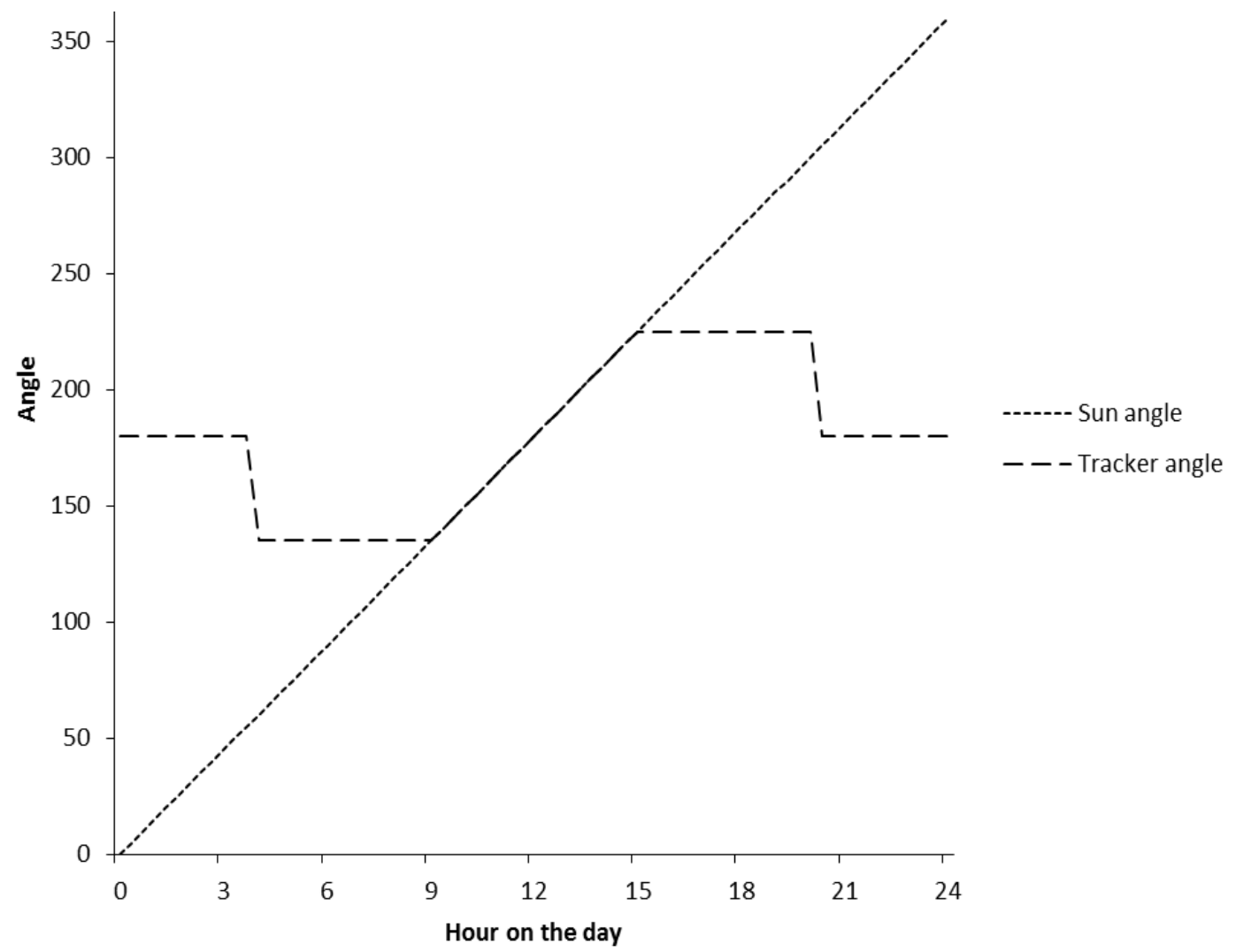

Figure 6. The lateral angle of the sun tracker as it mooves during the day. Sun in north $=0^{\circ}$, east $=90^{\circ}$, south $=180^{\circ}$ and west $=270^{\circ}$.

\section{CONCLUSION}

Plant movement is seen several places in nature. When plants grow it is very common that the tip of the growing area will orient itself towards the light - a phenomena referred to as phototropism. More interesting from an engineering point of view is the heliotropic movement where plants reversible move leaves, stems and flowers in order to track the sun. 
Flowers like the anemone and the snow buttercup are reported to do active tracking. Three different basic principles for sensing the direction of the sun and moving an object is described. For one of the principles a conceptual sun tracker has been developed. The sun tracker is capable of tracking the sun exactly within a sun angle of 90 degrees which is equivalent to 6 hours. In the remaining sun hours the efficiency will be lower since the angle to the sun is not optimal. In contrast to solar collectors mounted at a fixed angle the plant inspired sun tracker will collect light all day. When two collector systems are combined in a double axis system it will be possible to track the sun as it moves during the day but also compensate for the variation in sun height during the year. Each system is self-organised in a way similar to what is seen in plants since the movement is caused by a pressure difference that depend on the amount of incoming radiation. This also means that the system is insensitive to temperature variations in the surrounding environment.

\section{REFERENCES}

[1] Lewy, A. J., Bauer, V. K., Cutler, N. L., Sack, R. L., Ahmed, S., and Thomas, K. H.. "Morning vs. evening light treatment of patients with winter depression," Archives of General Psychiatry 55 (10), 890-896 (1998).

[2] Velux, "Sun Tunnels," http://www.velux.com/Products/Product range/Sun Tunnels, (09.02.2014)

[3] Solatube, "Solatubes," http://www.solatube.com/, (09.02.2014)

[4] Parens, "SP3 System," http://www.parans.com/, (09.02.2014)

[5] Ciralight, "SunTracker," http://www.ciralight.com/, (09.02.2014)

[6] Vagiakou, G., "Increasing daylight using sun tunnels in Greek private houses," Technical University of Denmark, Master thesis in the making (2014).

[7] Chen, Z. and Furbo, S., "Ydelse af trackende solfanger (performance of tracking solar collector)," Technical University of Denmark DTU Byg Rapport SR 11 (06), (2011).

[8] Lenau, T. and Hesselberg, T., [Engineered Biomimicry], Elsevier, 337-362 (2013).

[9] Tero, A., Takagi, S., Saigusa, T., Ito, K., Bebber, D. P. , Fricker, M. D., Yumiki, K., Kobayashi, R. and Nakagaki, T. "Rules for Biologically Inspired Adaptive Network Design," Science 327, 439-442 (2010).

[10] Billings, F.H., "A Study of Tillandsia usneoides," Botanical Gazette 38 (2), 99-121 (1904).

[11] Burgert, I. and Fratzl, P., "Actuation systems in plants as prototypes for bioinspired devices," Philosophical Transactions of the Royal Society Series A. 367, 1541-1557 (2009).

[12] Sundberg, S., "Size matters for violent discharge height and settling speed of Sphagnum spores: Important attributes for dispersal potential," Annals of Botany 105, 291-300 (2010).

[13] Zheng, H., Liu, Y. and Chen, Z., "Fast motion of plants: from biomechanics to biomimetics," Journal of Postdoctoral Research 1, 40-50 (2013).

[14] Forterre, Y., Skotheim, J. M., Dumais, J. \& Mahadevan, L., "How the Venus flytrap snaps," Nature 433, 421425 (2005).

[15] Zhang, S., Ai, H-L., Yu, W-B., Wang, H. and Li, D-Z.,"Flower heliotropism of Anemone rivularis (Ranunculaceae) in the Himalayas: effects on floral temperature and reproductive fitness," Plant Ecology, 209(2), 301-312 (2010).

[16] Martone, P. T., Boller, M., Burgert, I., Dumais, J., Edwards J., Mach, K., Rowe, N., Rueggeberg, M., Seidel, R. and Speck, T. "Mechanics without muscle: biomechanical inspiration from the plant world," Integrative and Comparative Biology 50, 888-907 (2010).

[17] Holmes, D. P. and Crosby, A. J., "Snapping surfaces," Advanced Materials 19, 3589-3593 (2007).

[18] Bathurst, S.P., Carvey, A.W., Cohen, E.D., Etra, J.V., Liau, F.W. and Whitfield, G.C, Thermal-Mechanical Positioning for Radiation Tracking, Patent application number: 20100275904 (2010).

[19] Iino, M., [Photomovement], Elsevier, 659-812 (2001).

[20] Leshem, Y., "Sunflower: a misnomer?" Nature, 269, 102 (1977).

[21] Shell, G.S.G., Lang, A.R.G. and Sale, P.J.M., "Quantitative Measures of Leaf Orientation and Heliotropic Response in Sunflower, Bean, Pepper and Cucumber," Agricultural Metrology, 13(1), 25-37 (1974).

[22] Went, F.W., "On growth-accelerating substances in the coleoptile of Avena sativa," Proc. Kon. Akad. Wetensch. Amsterdam, 30, I 0-19 (1926).

[23] Sherry, R.A. and Galen, C., "The mechanism of floral heliotropism in the snow buttercup, Ranunculus adoneus," Plant Cell Environ 21, 983-993 (1998).

[24] Hermansen, T., “Almanak," <http://www.torbenhermansen.dk/almanak> $>05.02 .2014)$ 